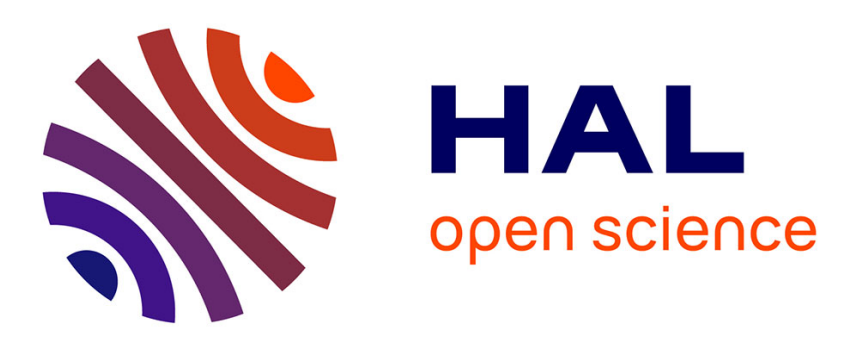

\title{
Mechanical Behavior And Modelisation Of Ti-6Al-4V Titanium Sheet Under Hot Stamping Conditions
}

Quentin Sirvin, Vincent Velay, Rébecca Bonnaire, Luc Penazzi

\section{To cite this version:}

Quentin Sirvin, Vincent Velay, Rébecca Bonnaire, Luc Penazzi. Mechanical Behavior And Modelisation Of Ti-6Al-4V Titanium Sheet Under Hot Stamping Conditions. ESAFORM 2017, Apr 2017, Dublin (et environs), Ireland. 10.1063/1.5007973 . hal-01615828

\section{HAL Id: hal-01615828 \\ https://hal.science/hal-01615828}

Submitted on 12 Oct 2017

HAL is a multi-disciplinary open access archive for the deposit and dissemination of scientific research documents, whether they are published or not. The documents may come from teaching and research institutions in France or abroad, or from public or private research centers.
L'archive ouverte pluridisciplinaire HAL, est destinée au dépôt et à la diffusion de documents scientifiques de niveau recherche, publiés ou non, émanant des établissements d'enseignement et de recherche français ou étrangers, des laboratoires publics ou privés. 


\title{
Mechanical Behavior And Modelisation Of Ti-6Al-4V Titanium Sheet Under Hot Stamping Conditions
}

\author{
Q. SIRVIN ${ }^{1, a)}$, V. VELAY ${ }^{1, b)}$, R. BONNAIRE ${ }^{1, c)}$ and L. PENAZZI ${ }^{1, d)}$ \\ ${ }^{1}$ Université de Toulouse; CNRS, Mines Albi, INSA, UPS, ISAE-SUPAERO ; ICA (Institut Clment Ader); Campus \\ Jarlard, F-81013 Albi, France.

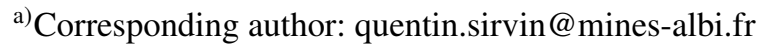 \\ b) vincent.velay@mines-albi.fr \\ ${ }^{\text {c) }}$ rebecca.bonnaire@mines-albi.fr \\ d)luc.penazzi@mines-albi.fr
}

\begin{abstract}
The Ti-6Al-4V titanium alloy is widely used for the manufacture of aeronautical and automotive parts (solid parts). In aeronautics, this alloy is employed for its excellent mechanical behavior associated with low density, outstanding corrosion resistance and good mechanical properties up to $600^{\circ} \mathrm{C}$. It is especially used for the manufacture of fuselage frames, on the pylon for carrying out the primary structure (machining forged blocks) and the secondary structure in sheet form. In this last case, the sheet metal forming can be done through various methods: at room temperature by drawing operation, at very high temperature $\left(\simeq 900^{\circ} \mathrm{C}\right)$ by superplastic forming (SPF) and at intermediate temperature $\left(\geq 750^{\circ} \mathrm{C}\right)$ by hot forming $(\mathrm{HF})$. In order to reduce production costs and environmental troubles, the cycle times reduction associated with a decrease of temperature levels are relevant. This study focuses on the behavior modelling of Ti-6Al-4V alloy at temperatures above room temperature to obtained greater formability and below SPF condition to reduce tools workshop and energy costs. The displacement field measurement obtained by Digital Image Correlation (DIC) is based on innovative surface preparation pattern adapted to high temperature exposures. Different material parameters are identified to define a model able to predict the mechanical behavior of Ti-6Al-4V alloy under hot stamping conditions. The hardening plastic model identified is introduced in FEM to simulate an omega shape forming operation.
\end{abstract}

\section{WHAT IS THE INTEREST IN Ti-6Al-4V TITANIUM ALLOY AND HOW ITS BEHAVIOR IS MODELISED?}

In the aeronautic industry, titanium alloys are very present principally due to high strength to weight ratio. This kind of material is largely used under sheet form structure and can be formed through three methods and three temperature ranges. At room temperature by drawing, at very high temperature (SPF conditions) by superplastic forming and at intermediate temperature by hot forming or hot stamping. In case of hot forming or stamping, the temperature is considered between $750^{\circ} \mathrm{C}$ and $890^{\circ} \mathrm{C}$ [1]. In order to energy cost saving and limit the environment impact, the development of this study is based on the reduction of the temperature range in hot forming operations.

This work aims to determine the parameters process to make the best use of the material behavior in order to optimize the forming of industrial parts in hot isothermal stamping. A literature review has brought together the material phenomena observed on the Ti-6Al-4V alloy. Thus, the anisotropy [2] [3], the strain rate sensitivity [4], the temperature effect [5] and the asymmetry behavior between tension/compression [2], are prominent phenomena to be considered in the behavior model formulation. Odenberger et al [6] and Tuninetti et al [7] shown that the yield criterion, developed by Cazacu et al [8], accurately describes the mechanical behavior, associed with temperature, of Ti-6Al-4V titanium alloy. The drawback of this criterion is the numbers of test. The study is developed around two approaches namely simple tensile test in large strain and hot forming test. Each test allows to determine some parameters. The simple tensile test in large strain allows to determine plastic behavior and limit formability of the material. Finally the hot forming test allows to compare the experimental results with the simulations and thus quantify the importance of each parameter. 


\section{PRESENTATION OF THE MATERIAL AND EXPERIMENTAL PROCEDURE USED TO IDENTIFY THE BEHAVIOR}

In this section, the microstructure of the material and the experimental procedures, namely tensile test in large strain, used to characterize the Ti-6Al-4V, are described. Secondly, the experimental test, that is hot forming test, is presented.

\section{The microstructure of Ti-6Al-4V material}

Specimens for the material test has been extracted from a plate with a $1.6 \mathrm{~mm}$ thickness provided by VSMPO. The heat treatment applied to this Ti-6Al-4V alloy sheet is $790^{\circ} \mathrm{C} / 45 \mathrm{~min}$ air cooling. The induced microstructure considers equiaxed $(\alpha+\beta)$ Ti-6Al-4V alloy with an average $\alpha$-phase grain size of 4 to $5 \mu \mathrm{m}$ as shown by figure 1 (a).
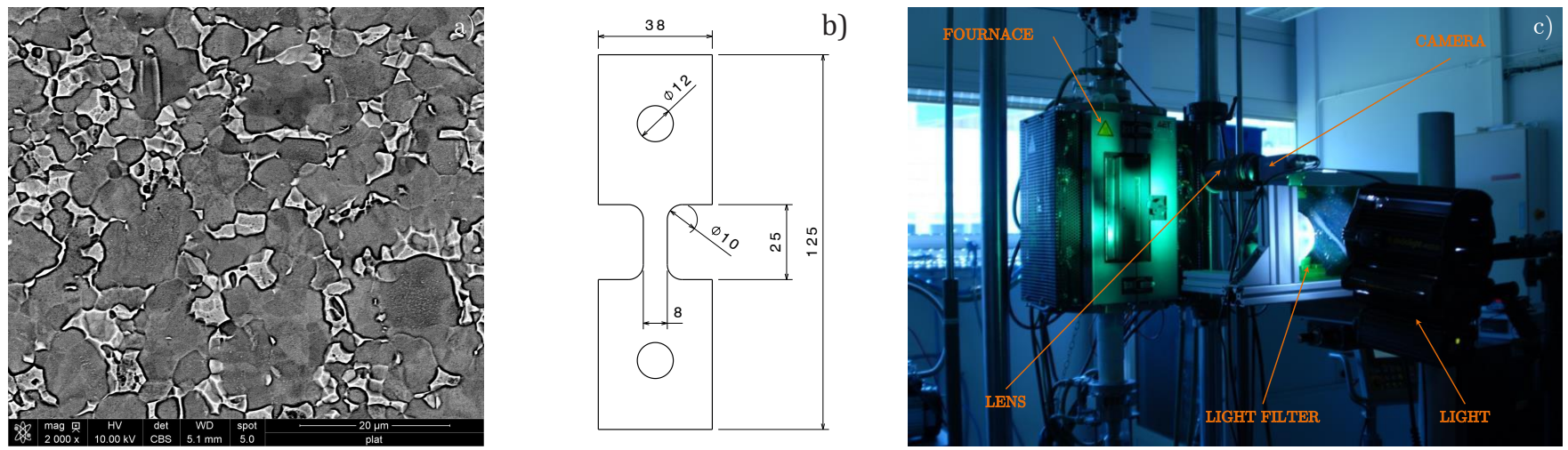

FIGURE 1. a) Micrography of Ti-6Al-4V titanium alloys at initial state; b) Illustration of specimen size; c) Photography of the device composed of a furnace, a lens, a camera, a light filter and a light.

\section{Experimental procedure to determine the different parameters: Anisotropy, Temperature effect and Strain Rate dependence}

To identify the plastic stain ratio, define by the equation 1 , we need to identify the transverse plastic strain rate $\left(\dot{\varepsilon}_{y y}^{p l}\right)$ and the thickness plastic stain rate $\left(\dot{\varepsilon}_{z z}^{p l}\right)$ during a tensile test carried out on a specimen taken in a direction establishing an angle $\alpha$ with the rolling direction. With the assumption of plastic incompressibility $\varepsilon_{x x}^{p l}+\varepsilon_{y y}^{p l}+\varepsilon_{z z}^{p l}=1$, only required the longitudinal $\left(\varepsilon_{x x}^{p l}\right)$ and transverse plastic strain $\left(\varepsilon_{y y}^{p l}\right)$ knowledge. These strains are calculated from the displacement field given by Digital Image Correlation (DIC) and allowed to acquire this data. The local plastic strain ratio is written as:

$$
r(\alpha)=\frac{\dot{\varepsilon}_{y y}^{p l}}{\dot{\varepsilon}_{z z}^{p l}}=-\frac{\varepsilon_{y y}^{p l}}{\varepsilon_{x x}^{p l}+\varepsilon_{y y}^{p l}}
$$

The dimensions of the specimen are described in figure 1 (b). The mechanical tensile tests were performed using a servo-hydraulic testing machine (MTS $50 \mathrm{kN}$ ), a furnace accurate for large elongations (AET) with three independent heating zones and an DIC bench composed of a lighting system, a green light filter, a camera 5 Mega Pixels (MP) and a fixed focal length lenses $28-300 \mathrm{~mm}$. As the use of a classic extensometer was not possible due to large elongation, a non-linear cross head displacement (defined by equation 2) was considered for all the mechanical tests in order to obtain a constant target strain rate $\dot{\varepsilon}$ at the center of the specimen [9].

$$
v=\dot{\varepsilon}_{x x} \cdot L_{0} \cdot \exp \left(\dot{\varepsilon}_{x x} \cdot t\right)
$$

The longitudinal strain field was measured by a non-contact technique based on DIC software Vic-2 $\mathrm{D}^{\mathrm{TM}}$. The figure 1 (c) shows the different components of the device. The surface marking of the specimen (speckle) is needed to achieve the image correlation using an innovative method: specimen anodizing. 
To characterize the anisotropy of the material, the tensile properties were evaluated along three directions in plane of Ti-6Al-4V sheet along the rolling (RD), transverse (TD), and at $45^{\circ}$ (DD) directions. In order to leave unchanged microstructure material, specimens were cut with water jet technology. Each test was duplicated three times if the results of the two first tests were different. This new equipment allows the measurements of large strain over a temperatures range from $20^{\circ} \mathrm{C}$ to $700^{\circ} \mathrm{C}$.

Additional to the longitudinal strain field measurement, the applied force was recorded by a load cell. We observed that the experimental data are disturbed by two phenomena: the variation, even minimal, of strain rate during a test and the measurement of deformation by DIC. To reduce the measurement uncertainty, a Savitzky Golay filter [10] was applied.

Figure 2 shows the temperature effect (a) and the strain rate dependence (b). For each graph, normalization was carried out, for stress, from maximum stress at the end of test for lowest temperature and higher strain rate, for strain, from maximum strain before necking for higher temperature and lower strain rate. Notice that stress level decreasing with temperature rising and with strain rate decreasing. The maximal strain obtained for each test condition is the strain value before necking.
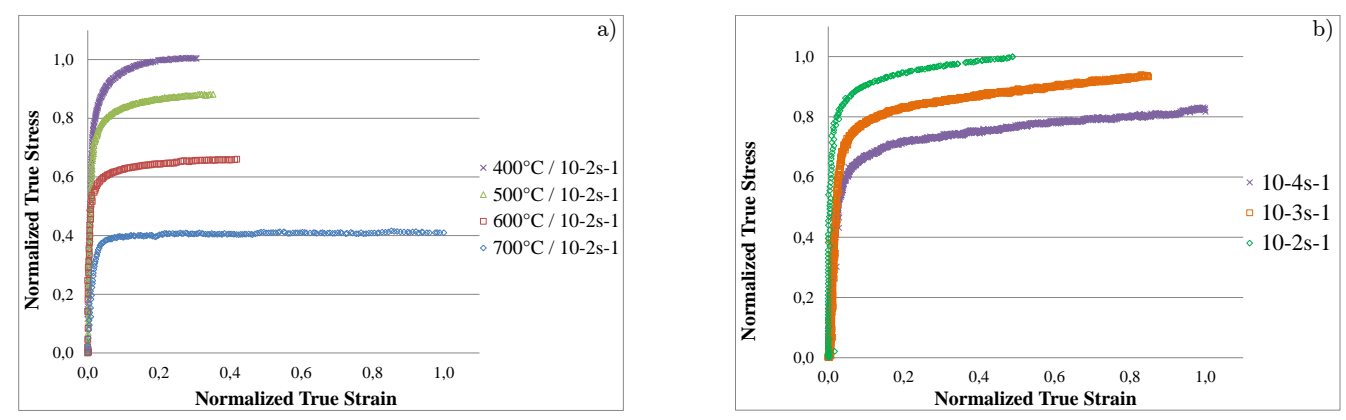

FIGURE 2. Normalized true stress vs Normalized true strain of Ti-6Al-4V titanium alloy: a) temperature effect from $400^{\circ} \mathrm{C}$ to $700^{\circ} \mathrm{C}$ and $10^{-2} \mathrm{~s}^{-1}$ strain rate ; b) strain rate dependence for DD sampling direction at $500^{\circ} \mathrm{C}$ and three strain rate: $10^{-2} \mathrm{~s}^{-1}, 10^{-3} \mathrm{~s}^{-1}$, $10^{-4} \mathrm{~s}^{-1}$.

The experimental curves along the three directions (RD, DD and TD) are shown in Figure 3 a) and highlight the anisotropy. Here the influence of the extract angle $(\alpha)$ at $400^{\circ} \mathrm{C}$ and $10^{-4} \mathrm{~s}^{-1}$ strain rate is shown. Note that for others temperatures and strain rates studied, the conclusions are the same: the material is strongest for $\alpha=0^{\circ}$ direction and weakest for $\alpha=45^{\circ}$ direction. The elongation before necking $\left(\varepsilon_{x x}\right)$ is maximal for $\alpha=0^{\circ}$ and minimal for $\alpha=90^{\circ}$. In Figure $3 \mathrm{~b}$ ) the evolution of normalized plastic strain ratio is shown. The normalization was carried out from maximum mean plastic strain ratio cacluled from $r_{m}=\frac{r_{0}+2 r_{4}+r_{90}}{4}$. These results show that the anisotropy is a little less marked when the temperature decreased. The evolution of the plastic strain ratio presented in this paper is in a good agreement with the results presented by Odenberger et al [6] or Chartrel et al [3]. Afterwards, the influence of each previous phenomenon on the hot forming process is analysed. For that purpose, an omega shape forming is conducted experimentally.

\section{Forming Omega test}

These tests, derived from the NUMISHEET '93 [11] and based on those realized by Odenberger et al [12], will be able to quantify spring back by three-dimensional measurement of work-piece after forming. With this test, the force applied by punch and the displacement of specimen during test will be compared to FE simulation (described in section SIMULATION). The sheet metal forming tests were performed under isothermal conditions and using a tool set composed of punch, die and blank-holder manufactured in X38-Cr-Mo-V5 tool steel with $48 \mathrm{HRC}$ hardness. In these experiments, the hydraulic testing machine (MTS $50 \mathrm{kN}$ ) was stroked displacement controlled before switching to load controlled at the very end of the forming sequence. All tests are isothermal and were performed in a furnace (AET) as as illustrated in figure 4 (a). Two types of specimens were tested, one type extracted from along the rolling direction (RD), another one extracted from transverse direction (TD). The dimensions of the sheet specimens were $205 \mathrm{~mm} \times 30 \mathrm{~mm}$ and those of the forming tools are described in figure 4 (b). Sheet specimens were cut by water jet 

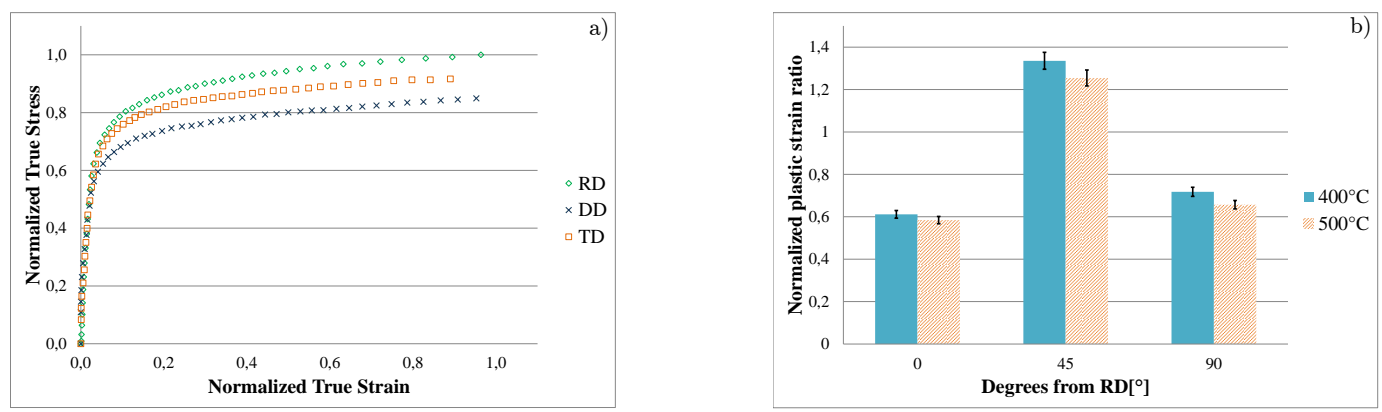

FIGURE 3. a) Uniaxial tensile test in three in-plane orientations showing the material's anisotropy in tension at $400^{\circ} \mathrm{C}$ and $10^{-4} \mathrm{~s}^{-1}$ strain rate; b) Evolution of normalized plastic strain ratio with the temperature and degrees from RD.

technology, ground with abrasive paper to remove oxide layers and sprayed with Boron Nitride Aerosol as lubrication. The sheet specimens were placed and centred in the forming tool after which the forming sequence was carried out. The lower die had a constant velocity of 0.5 or $10 \mathrm{~mm} / \mathrm{s}$. A holding time of X seconds was applied before unloading ( $\mathrm{X}$ is a variable that evolves according to the differents tests).
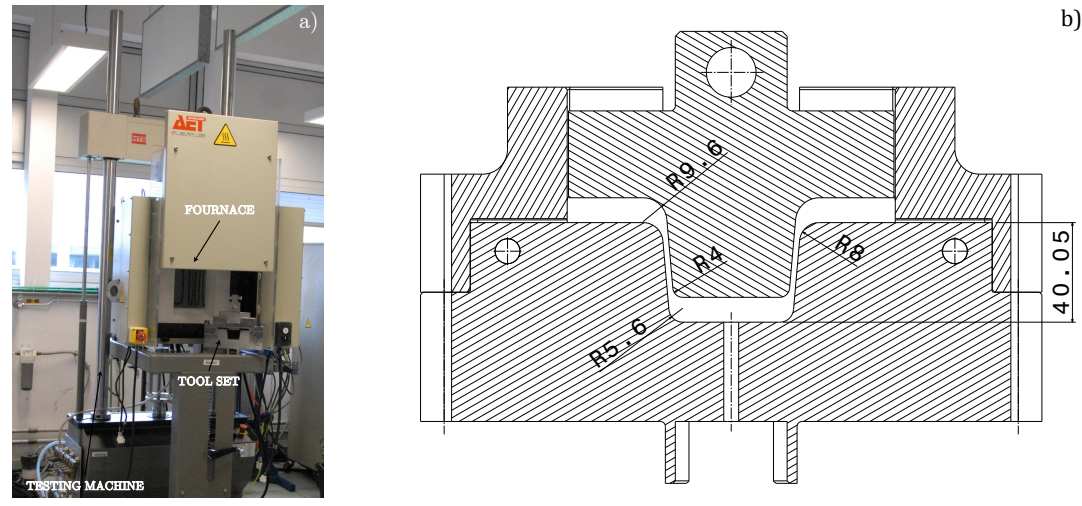

FIGURE 4. a)Photography of the experimental device, b) Drafting with general dimensions of the forming omega tools.

\section{SIMULATION OF THE EXPERIMENTAL OMEGA SHAPE FORMING OPERATION}

In the present work the implicit FE-code abaqus $6.14^{\circledR}$ has been used for solving the equations of motion. Complex geometries in industrial applications with large deformations, non-linear materials and contacts can be treated effectively and quickly. In the virtual tool design performed in the present work different forming concepts, temperatures and tool features are evaluated. To validate the mechanical behavior model, the punch force, the displacement and the thickness of the specimen predicted by FEM and obtained by experimental Omega shape were compared. The simulation model uses a quarter of the real Omega shape. A 3D discrete rigid tool (punch, die and blank-holder) with 4 node, bilinear quadrilateral elements (R3D4) and 3D solid homogeneous deformable specimen using 8-node brick element (C3D8) are used. The material is described by an elasto-visco-plastic behavior. The elastic part is isotropic (E, $v, \alpha$ ). The plastic part is actually constituted by an anisotropic yield criterion (Hill), with isotropic hardening evolution and a hardening law with strain rate dependence.

An example of FE-model result is shown in figure 5. In this case an anisotropic yield criterion (Hill) with isotropic hardening evolution and a hardening law with strain rate dependence is taking in to account. The boundary condition are $0.5 \mathrm{~mm} / \mathrm{s}$ punch velocity and blank-holder displacement about $0.1 \mathrm{~mm}$. The contact between specimen and tools 
is described by surface-to-surface contact (Coulomb's law) with friction coefficient of 0.2 as defined by Semiatin et al [13] in their work on the hot workability of titanium alloys. The average calculation time for one forming step, with an Intel ${ }^{\circledR}$ Core $^{\mathrm{TM}}$ i5 CPU @ $1.70 \mathrm{GHz}$ and $8.00 \mathrm{Go}$ RAM, is about 45 hours. Each FE simulation addresses different complexity levels regarding the implemented behavior model formulation.

The figure 5 (a) gives the Von Mises stress map on the top of the specimen at the end of punch displacement. At this step, the maximal stress is located at the entry at the input radius die ( $960 \mathrm{MPa})$. The results of these FE simulation are compared to experimental forming tests (see figure 5 (b)) in term of punch force - time. On this graph we can see that the punch force is nearly constant from 20 seconds $(10 \mathrm{~mm})$ to 78 seconds $(38 \mathrm{~mm})$. Beyond this value, the punch force increases rapidly in part due to thickness compression on specimen. On this interval, we can see a discrepancy about $20 \%$ between FE simulation and experimental test.
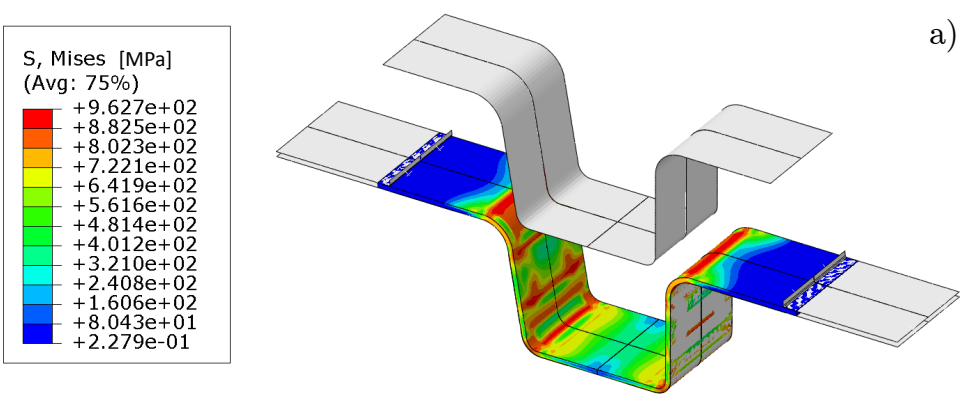

a)

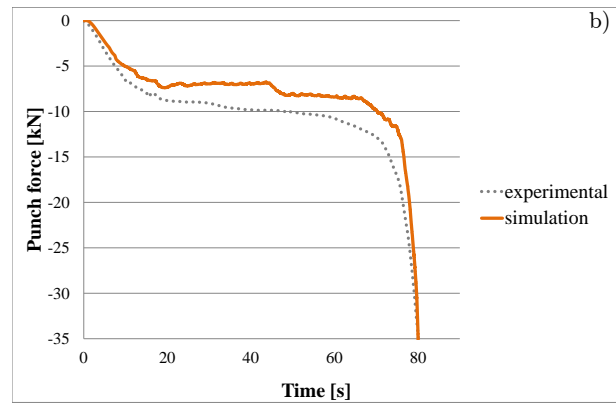

FIGURE 5. FE Modelling a single drawing omega operation a) Von Mises map on the top face at the end of the punch displacement; b) Evolution of the punch force over time.

\section{DISCUSSION ABOUT Ti-6Al-4V TITANIUM ALLOYS BEHAVIOR WITH PHENOMENONS}

This study deals with the development of an experimental tests device to perform mechanical tests in hot isothermal conditions and under large deformation conditions.

There are few results from the literature for such experimental conditions (temperature between $400^{\circ} \mathrm{C}$ to $700^{\circ} \mathrm{C}$, strain rate between $10^{-4} \mathrm{~s}^{-1}$ to $10^{-2} \mathrm{~s}^{-1}$ and anisotropy). This work shows the influence of several key parameters on the material behavior. Thus the stain rate sensibility for the three strain rates $\left(10^{-2} \mathrm{~s}^{-1}, 10^{-3} \mathrm{~s}^{-1}, 10^{-4} \mathrm{~s}^{-1}\right)$ at $500^{\circ} \mathrm{C}$ showed a decrease of the stress level and an increase of the elongation before necking with the stain rate. This conclusion is in agreement with the study carried out by Majorell et al [4]. The material exhibits a temperature sensitivity $\left(400^{\circ} \mathrm{C}\right.$ to $700^{\circ} \mathrm{C}$ ), a better formability and a more important elongation when the temperature rises. At the temperature considered in this work, the anisotropy is marked and strengthens the results provided by Chartrel et al. [3] for higher temperatures. All these phenomena influence the Ti-6Al-4V behavior and must be taken into account during the forming operations at high temperature.

The punch force comparison between experimental device of Omega shape and simulation shows that the material law implemented in the FE-model could be improved in order to more accurately describe the punch force.

In order to improve the mechanical testing database and assess, more precisely, the yield stress and the asymmetry behavior, tension-compression and compression-tension testing are in progress.

\section{ACKNOWLEDGEMENTS}

The authors gratefully acknowledge the two companies Aurock and Loire Etude are also acknowledged for financial support. Special thank for all the laboratory technicians: T. Papaïx, D. Ade, J.-M. Mouys and S. Tovar for their help. 


\section{REFERENCES}

[1] L. F. G. Stutz, W. F. G. Beck, S. F. G. Arends, V. H. Ventzke, and N. H. Kashaev, 9th European Conference on Superplastic Forming 841-846 (2013).

[2] G. Gilles, W. Hammami, V. Libertiaux, O. Cazacu, J. Yoon, T. Kuwabara, A. Habraken, and L. Duchêne, International Journal of Solids and Structures 48, 1277-1289may (2011).

[3] B. Chartrel and E. Massoni, 557, 190-195 (2013).

[4] A. Majorell, S. Srivatsa, and R. C. Picu, Materials Science and Engineering a-Structural Materials Properties Microstructure and Processing 326, 297-305 (2002).

[5] S. Nemat-Nasser, W. G. Guo, V. F. Nesterenko, S. S. Indrakanti, and Y. B. Gu, Mechanics of Materials 33, 425-439 (2001).

[6] E.-1. Odenberger, "Material Characterisation for Analyses of Titanium Sheet Metal Forming," Ph.D. thesis 2005.

[7] V. Tuninetti, G. Gilles, O. Milis, T. Pardoen, and A. M. Habraken, International Journal of Plasticity 67, 53-68 (2015).

[8] O. Cazacu, B. Plunkett, and F. Barlat, International Journal of Plasticity 22, 1171-1194jul (2006).

[9] N. Kotkunde, H. N. Krishnamurthy, P. Puranik, A. K. Gupta, and S. K. Singh, Materials and Design 54, 96-103 (2014).

[10] A. Savitzky and M. J. E. Golay, 36, 1627-1639 (1964).

[11] A. Makinouchi, NUMISHEET '93: proceedings of the 2nd International Conference Numerical Simulation of 3-D Sheet Metal Forming Processes ; verification of simulation with experiment ; Isehara, Japan, 31. August - 2. September 1993 (1993).

[12] E.-L. Odenberger, R. Pederson, and M. Oldenburg, Materials Science and Engineering: A 489, 158-168 (2008).

[13] S. Semiatin, V. Seetharaman, and I. Weiss, Materials Science and Engineering: A 243, 1-24 (1998). 